\title{
DIMENSI METRIK PADA HASIL OPERASI KORONA DUA BUAH GRAF
}

\author{
Silviana Maya P. ${ }^{1}$, Syarifuddin N. Kapita ${ }^{2}$ \\ ${ }^{1}$ Peniddikan Mateatika, Fakultas Keguruan dan Ilmu Pendidikan, Universitas PGRI Adi Buana Surabaya \\ ${ }^{2}$ Pendidikan Matematika, Fakultas Keguruan dan Ilmu Pendidikan,Universitas Khairun \\ smaya@unipasby.ac.id ${ }^{1}$, syarifkapita@gmail.com ${ }^{2}$
}

\begin{abstract}
Abstrak
Misalkan $G$ didefinisikan sebagai graf terhubung dengan $V(G)$ himpunan titik pada graf $G$ dan $W=\left(w_{1}, w_{2}, \ldots, w_{k}\right)$ himpunan titik pada graf $G$ yang anggotanya telah ditentukan. Representasi titik $u$, untuk setiap $u \in V(G)$ terhadap W dinotasikan dengan $r\left(u_{w} W\right)$ di $G$ merupakan jarak titik $u$ pada tiap anggota di $W$ atau dapat dituliskan sebagai $(u \mid W)=d\left(u_{v} w_{1}\right), d\left(u, w_{2}\right), \ldots, d\left(u, w_{k}\right)$. Himpunan W disebut himpunan pemisah pada $\mathrm{G}$ jika dan hanya jika untuk setiap u,v pada $\mathrm{G}$ dan $u \neq v$ mengakibatkan $r(u \mid W) \neq r(v \mid W)$. Dimensi metrik pada $G$ dinotasikan dengan $\operatorname{dim}(G)$ merupakan kardinalitas minimum dari semua himpunan pemisah pada $G$. Operasi korona pada dua buah graf $\mathrm{G}$ dan $\mathrm{H}$ dinotasikan dengan $G \odot H$.
\end{abstract}

Kata Kunci: dimensi metrik, himpunan pemisah, representasi metrik, operasi korona

\section{PENDAHULUAN}

Teori graph pertama kali diperkenalkan pada Tahun 1736 melalui tulisan Euler yang berisi tentang upaya pemecahan masalah jembatan Konigsberg di Eropa, yakni membuktikan kemungkinan untuk/melewati empat daerah yang terhubung dengan tujuh jembatan tersebut dalam sekali waktu. Euler merepresentasikan masalah tersebut dalam graf dan menyatakan keempat daerah itu sebagai titik, sedangkan ketujuh jembatan sebagai sisi yang menghubungkan pasangan titik yang sesuai. Dari percobaan yang ia lakukan, disimpulkan bahwa tidak mungkin bisa melalui setiap jembatan dan kembali lagi ke tempat semula dalam sekali waktu, maka untuk itu jumlah jembatan yang menghubungkan setiap daratan harus genap.

Kurang lebih seratus tahun setelah lahirnya tulisan tersebut tidak ada perkembangan yang berarti berkenaan dengan teori graph, lalu pada tahun 1847 , G.R. Kirchoff $(1824-1887) \quad$ berhasil mengembangkan teori pohon (Theory of trees) yang digunakan dalam persoalan jaringan listrik. Konsep yang sama juga digunakan A. Coyley (1821 - 1895) untuk menjelaskan permasalahan kimia, sepuluh tahun kemudian.

Salah satu topik dalam teori graf yang menarik untuk dikaji adalah dimensi metrik. Muzayyana, misalnya, meneliti dimensi metrik pada graf lintasan tak hingga. Tahun 2011, penelitian mengenai dimensi metrik ini dikembangkan oleh Arum Melati dengan mengangkat kajian dimensi metrik pada graf lengkap, graf lintasan dan graf bipartit lengkap. Eka dan Budi melengkapi penelitian yang serupa pada graf sikel dan graf bintang, pada tahun 2013.

Dimensi metrik adalah kardinalitas minimum dari semua himpunan pemisah pada $G$ yang dinotasikan dengan $\operatorname{dim}(G)$. Misalkan u dan v adalah dua titik pada graf terhubung G. Jarak dari $\mathrm{u}$ ke $\mathrm{v}$ adalah panjang lintasan terpendek antara $\mathrm{u}$ dan $\mathrm{v}$ pada $\mathrm{G}$ yang dinotasikan dengan $\mathrm{d}(\mathrm{u}, \mathrm{v})$.

Hasil korona pada dua buah graf $G$ dan $H$, dinotasikan dengan $G \odot H$.

\section{DASAR TEORI}

\section{Teori Dasar Graf}

Graf $G$ dinotasikan dengan $G=(V, E)$ berisikan sepasang himpunan, yakni himpunan simpul/ titik berhingga tak kosong $V(G)$ dan himpunan sisi berhingga (mungkin kosong) $E(G)$, sedemikian hingga 
setiap elemen $e$ dalam $E(G)$ merupakan pasangan tak berurutan dari titik-titik di $V(G)$.

Ada pun beberapa jenis graf yang akan kita bahas dalam paper ini adalah graf lintasan dan graf sikel. Graf lintasan, dinotasikan dengan $P_{\mathrm{n}}$ adalah graf yang derajat simpul selain ujungnya adalah 2 , sedangkan graf sikel, dinotasikan dengan $C_{\text {n }}$ adalah graf terhubung dengan $n$ titik yang mempunyai tepat satu sikel dengan panjang $n$. Graf bintang, dinotasikan dengan $K_{1 \text { n-1 }}$ adalah graf bipartit komplit dengan $n$ titik.

\section{Himpunan Pemisah}

Misalkan $W=\left(w_{1}, w_{2}, \ldots, w_{k}\right)$ adalah himpunan titik pada graf $G$ yang anggota-anggotanya telah ditentukan. Representasi titik $u \in V(G)$ terhadap $W$ di $G$ adalah $k$-tupel, dinotasikan dengan $r(u, W)$ di $G$ merupakan jarak titik $u$ pada tiap anggota di $W$ atau dapat dituliskan sebagai $(u \mid W)=\left(d\left(u_{v}, w_{1}\right), d\left(u, w_{2}\right){ }_{s, n} d\left(u_{v}, w_{k}\right)\right.$. Himpunan $W$ disebut himpunan pemisah pada $G$ jika dan hanya jika untuk setiap $u, v$ pada $G$ dan $u \neq v$ mengakibatkan $r(u \mid W) \neq r(v \mid W)$.

\section{Operasi Korona}

Operasi korona pada dua buah graf $\mathrm{G}$ dan $\mathrm{H}$, dinotasikan dengan $G \odot H$, didefinisikan sebagai graf yang diperoleh dari salinan $\mathrm{p}$-simpul graf $\mathrm{G}$ dan $\mathrm{p}$ salinan $H_{1}, H_{2, \ldots,} H_{p}$ dari $\mathrm{H}$, yang kemudian bergabung dengan i-simpul dari $\mathrm{G}$ untuk setiap simpul di $H_{i}$.

Kita definisikan $V(G \odot H)=V(G) \cup\{(a, v) \mid a \in V(G), v \in V(H), a v \in$ $V(G \odot H)$

\section{Contoh:}

a. $P_{\mathrm{a}} \odot C_{4}$

$$
P_{3}
$$

Gambar 1. Graf Lintasan dengan 3 Titik

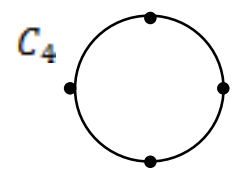

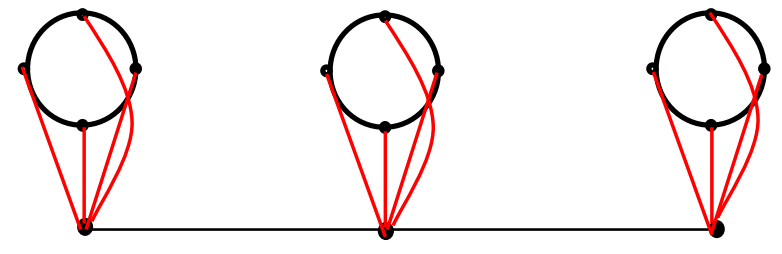

Gambar 3. Graf $P_{\mathrm{a}} \odot C_{4}$

b. $P_{\mathrm{a}} \odot K_{1,5}$

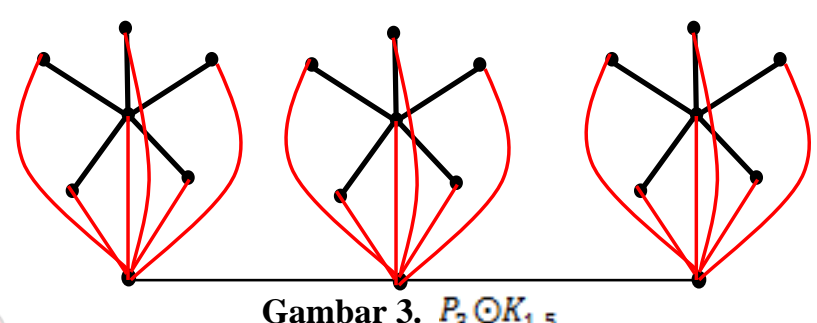

Gambar 3. $P_{9} \odot K_{1,5}$

\section{PEMBAHASAN}

\section{Dimensi Metrik pada Graf}

Dimensi metrik pada $G$ dinotasikan dengan $\operatorname{dim}(G)_{x}$ adalah kardinalitas minimum dari semua himpunan pemisah pada $G$.

Contoh:

G

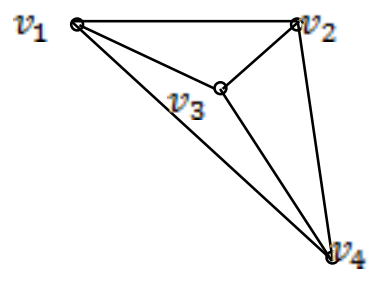

Gambar 4. Graf Lengkap dengan 4 Titik

Dipilih $W_{1}=\left\{v_{1}\right\}$, representasi setiap titik pada $G$ terhadap $W_{1}$ adalah $r\left(v_{1} \mid W_{1}\right)=(0), r\left(v_{2} \mid W_{1}\right)=(1)$, $r\left(v_{a} \mid W_{1}\right)=(1), \quad r\left(v_{4} \mid W_{1}\right)=(1)$. Karena ada $v_{2}, v_{a}, v_{4}$ dan $v_{2} \neq v_{a} \neq v_{4}$ tetapi ), $r\left(v_{2} \mid W_{1}\right)=r\left(v_{a} \mid W_{1}\right)=r\left(v_{4} \mid W_{1}\right)$ maka $\mathrm{W}$ dengan kardinalitas 1 bukan himpunan pemisah, sehingga $\operatorname{dim}(G) \neq 1$

Dipilih $W_{2}=\left\{v_{1}, v_{2}\right\}$, representasi setiap titik pada $G$ terhadap $W_{2}$ adalah $r\left(v_{1} \mid W_{2}\right)=(0,1)$, $r\left(v_{2} \mid W_{2}\right)=(1,0), \quad r\left(v_{a} \mid W_{2}\right)=(1,1)$, $r\left(v_{4} \mid W_{2}\right)=\left(1_{s} 1\right)$. Karena ada $v_{a}, v_{4}$ dan $v_{a} \neq v_{4}$ tetapi $), \quad r\left(v_{a} \mid W_{2}\right)=r\left(v_{4} \mid W_{2}\right)$ maka $W$ dengan kardinalitas 2 bukan himpunan pemisah, sehingga 
$\operatorname{dim}(G) \neq 2$

Dipilih $W_{3}=\left\{v_{1}, v_{2}, v_{2}\right\}$, representasi setiap titik pada $G$ terhadap $W_{a}$ adalah $r\left(v_{1} \mid W_{a}\right)=(0,1,1)$, $r\left(v_{2} \mid W_{a}\right)=(1,0,1), \quad r\left(v_{a} \mid W_{a}\right)=(1,1,0)$, $r\left(v_{4} \mid W_{a}\right)=(1,1,1)$. Karena untuk setiap $u_{v} v \in V(G), u \neq v$ dan $r\left(u \mid W_{a}\right) \neq r\left(v \mid W_{a}\right)$, maka W dengan kardinalitas 3 adalah himpunan pemisah. Jadi, $\operatorname{dim}(G)=3$.

\section{Teorema-teorema Pendukung}

a. Graf terhubung dengan $n$ titik mempunyai dimensi 1 jika dan hanya jika $G=P n$.

b. Jika $G$ graf sikel dengan n titik dan $n \geq 3$, maka $\operatorname{dim}\left(C_{n}\right)=2$.

c. Jika $u, v \in V(G)$ dan $d(u, W)=d(v, W)$ untuk $W \in V(G)-\{u, v\}$ maka $u$ dan $v$ harus berada pada partisi yang berbeda.

\section{Dimensi Metrik Pada Hasil Operasi Korona Dua Buah Graf}

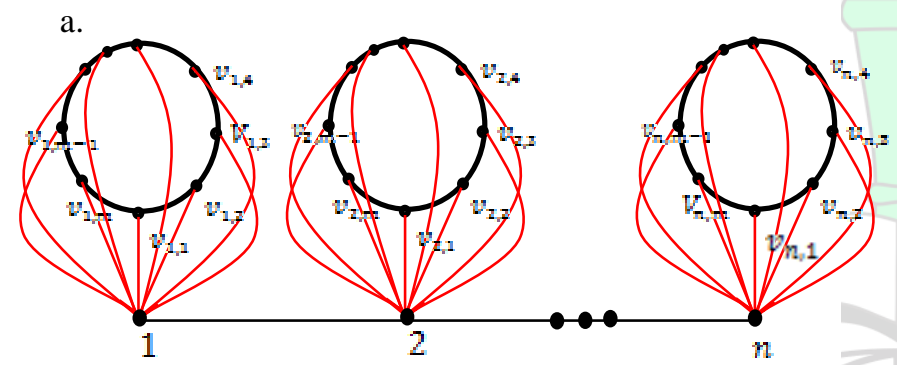

Gambar 4. Graf $P_{n} \odot C_{m}$

\section{Teorema}

Jika $\mathrm{G}$ adalah graf hasil operasi korona graf lintasan $\left(P_{n}\right)$ dengan $n$ titik dan graf sikel $C_{m}$ dengan $m$ titik, dimana $n \geq 2$ dan $m \geq 5$, maka $\operatorname{dim}(G)$ dengan $W=\left\{v_{1,1}, v_{1,2}, \ldots, v_{1, n-4}, v_{1, m-a^{*}}, v_{2,1}\right.$,

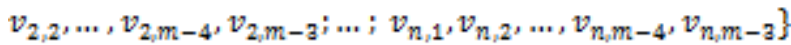
adalah $n(m-3)$.

\section{Bukti:}

Akan dibuktikan bahwa $|W|=n(m-3)$ adalah himpunan pemisah. Representasi setiap titik pada $G$ terhadap $\mathrm{W}$ adalah

$$
\begin{aligned}
& r\left(v_{2, m} \mid W\right)=\{3,3, \ldots, 3,3 ; 1,2, \ldots, 2,2 ; \ldots ; n, n, \ldots, n, n\} \\
& r(n \mid W)=\left\{n, n_{x \ldots,} n, n_{;} \ldots ; 3,3, \ldots, 3,3 ; 2,2, \ldots, 2,1\right\} \\
& r\left(v_{n m-2} \mid W\right)=\left\{n+1_{v} n+1_{m \ldots} n+1_{s} n+1 ; \ldots ; 3,3, \ldots, 3,3 ; 2,2, \ldots, 2,1\right\} \\
& r\left(v_{n m-1} \mid W\right)=\left\{n+1, n+1_{y, n} n+1_{s} n+1 ; \ldots ; 3,3, \ldots, 3,3 ; 2,2, \ldots, 2,2\right\} \\
& r\left(v_{n, m} \mid W\right)=\left\{n+1, n+1_{s \ldots} n+1, n+1_{j \ldots} ; 3,3, \ldots, 3,3 ; 1,2, \ldots, 2,2\right\}
\end{aligned}
$$

Pemeriksaan hanya perlu dilakukakan pada titiktitik yang tidak termasuk anggota W, sebab untuk representasi titik-titik yang merupakan anggota dari $\mathrm{W}$, akan memiliki representasi unik yang pasti akan selalu berbeda pada posisi angka nol-nya. Karena untuk setiap $u_{v} v \in V(G), u \neq v$ dan $r(u \mid W) \neq r(v \mid W)$, maka $W$ dengan kardinalitas $n(m-3)$ himpunan pemisah.

Akan dibuktikan $\mathrm{W}$ dengan kardinalitas $n(m-3)$ adalah himpunan pemisah dengan kardinalitas minimum. Misalkan ada himpunan pemisah $W=$

$\left\{V_{1,1}, v_{1,2}, \ldots, v_{1, m-5}, V_{1, m-4}, V_{2,1}, v_{2,2}, \ldots, v_{2, m-5}, V_{2, m-4} ;\right.$

$\left.\ldots v_{n, 1}^{*}, v_{n, 2}, \ldots, v_{n, m-5}, v_{n, m-4}\right\}, \quad$ dengan $|W|=n(m-4)$. Representasi setiap titik di $G$ terhadap $W$ adalah

$$
\begin{aligned}
& r(1 \mid W)=\left\{1,1, \ldots, 1,1 ; 2,2, \ldots, 2,2 ; \ldots ; n, n_{v} \ldots, n, n\right\} \\
& r\left(v_{1, m-a} \mid W\right)=\{2,2, \ldots, 2,1 ; 3,3, \ldots, 3,3 ; \ldots ; n+1, n+1, \ldots, n+1, n+1\}
\end{aligned}
$$

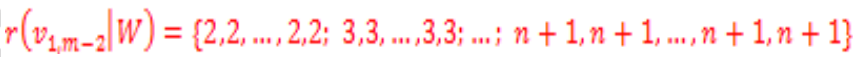

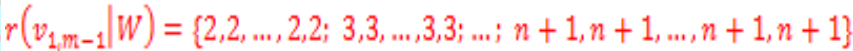

$$
\begin{aligned}
& r\left(v_{1, m} \mid W\right)=\{1,2, \ldots, 2,2 ; 3,3, \ldots, 3,3 ; m ; n+1, n+1, \ldots, n+1, n+1\} \\
& r(2 \mid W)=\left\{2,2, \ldots, 2,2 ; 1,1_{j}, 1_{j} 1_{j \ldots} ; n-1, n-1, \ldots, n-1, n-1\right\} \\
& r\left(v_{2, m-a} \mid W\right)=\left\{3,3, \ldots, 3,3 ; 2,2, \ldots, 2,1 ; \ldots ; n, n_{v \ldots,} n, n\right\}
\end{aligned}
$$

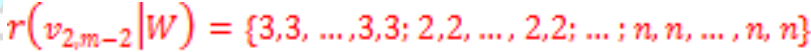

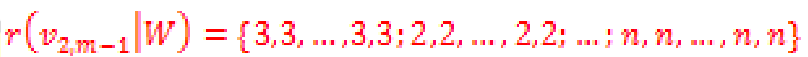

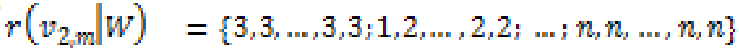

$$
\begin{aligned}
& r(n \mid W)=\left\{n, n_{v} \ldots, n, n_{;} \ldots ; 3,3, \ldots, 3,3 ; 2,2, \ldots, 2,1\right\} \\
& r\left(v_{n m-a} \mid W\right)=\{n+1, n+1, \ldots, n+1, n+1 ; \ldots ; 3,3, \ldots, 3,3 ; 2,2, \ldots, 2,1\}
\end{aligned}
$$

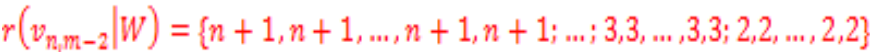

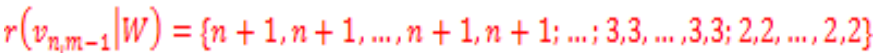

$$
\begin{aligned}
& r\left(v_{n, m} \mid W\right)=\{n+1, n+1, \ldots, n+1, n+1 ; \ldots ; 3,3, \ldots, 3,3 ; 1,2, \ldots, 2,2\}
\end{aligned}
$$

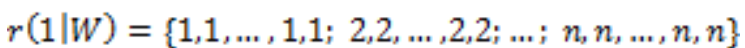

$r\left(v_{1, n-2} \mid W\right)=\{2,2, \ldots, 2,1 ; 3,3, \ldots, 3,3 ; \ldots ; n+1, n+1, \ldots, n+$ $r\left(v_{1, m-1} \mid W\right)=\{2,2, \ldots, 2,2 ; 3,3, \ldots, 3 ; \ldots ; n+1, n+1, \ldots, n+1, n+1\}$ $r\left(v_{1, m} \mid W\right)=\{1,2, \ldots, 2,2 ; 3,3, \ldots, 3,3 ; \ldots ; n+1, n+1, \ldots, n+1, n+1\}$ $r(2 \mid W)=\{2,2, \ldots, 2,2 ; 1,1, \ldots, 1,1 ; \ldots ; n-1, n-1, \ldots, n-1, n-1\}$ $r\left(v_{2, m-2} \mid W\right)=\{3,3, \ldots, 3,3,2,2, \ldots, 2,1 ; \ldots ; n, n, \ldots, n, n\}$. $r\left(v_{2, m-1} \mid W\right)=\{3,3, \ldots, 3,3,2,2, \ldots, 2,2 ; \ldots ; n, n, \ldots s, n, n\}$

Ada

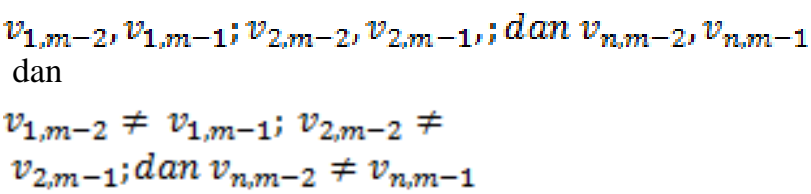


tetapi,

$r\left(v_{1, m-2} \mid W\right)=r\left(v_{1, m-1} \mid W\right) ; r\left(v_{2, m-2} \mid W\right)=$

$r\left(v_{1, m} \mid W\right)=(1 ; 2,2, \ldots 2 ; 3 ; 3,3, \ldots 3 ; \ldots ; n+1 ; n+1, n+1, \ldots, n+1$

$r\left(v_{2, m-1} \mid W\right)$; dan $r\left(v_{n, m-2} \mid W\right)=$

$r\left(v_{n, m-1} \mid W\right)$

$r\left(v_{2, m} \mid W\right)=(3 ; 3,3, \ldots 3 ; 1 ; 2,2, \ldots 2 ; \ldots ; n ; n, n, \ldots n)$

:

Maka W dengan kardinalitas $n(m-4)$ bukan himpunan pemisah. Oleh karena itu, tidak terdapat himpunan pemisah dengan kardinalitas kurang dari $n(m-3)$, sehingga $\mathrm{W}$ dengan kardinalitas $n(m-3)$ adalah himpunan pemisah dengan kardinalitas minimum.

Jadi, terbukti jika $G$ adalah graf hasil operasi korona graf lintasan $\left(P_{n}\right)$ dengan $n$ titik dan graf sikel $C_{m}$ dengan $m$ titik, dimana $n \geq 2$ dan $m \geq 5$, maka $\operatorname{dim}(G) \quad$ dengan $W=$ $r\left(v_{n, m} \mid W\right)=(n+1 ; n+1, n+1, \ldots, n+1 ; n ; n, n, \ldots n ; \ldots ; 1 ; 2 ; 2,2$,

Pemeriksaan hanya perlu dilakukakan pada titik-titik yang tidak termasuk anggota $\mathrm{W}$, sebab untuk representasi titik-titik yang merupakan anggota dari $\mathrm{W}$, akan memiliki representasi unik yang pasti akan selalu berbeda pada posisi angka nol-nya. Karena untuk setiap $u, v \in V(G), u \neq v$ dan $r(u \mid W) \neq r(v \mid W)$, maka $\mathrm{W}$ dengan kardinalitas $n m$ adalah himpunan pemisah.

Akan dibuktikan $W$ dengan kardinalitas $n m$ adalah himpunan pemisah dengan kardinalitas minimum. Misalkan ada himpunan pemisah

$\left\{v_{1,1}, v_{1,2}, \ldots, v_{1, m-4}, v_{1, m-a^{\prime}} ; v_{2,1}, v_{2,2}, \ldots, v_{2, m-4}, v_{2, m-a^{\prime}} ;: v_{1,} W=\right.$
adalah $n(m-3)$.

b.

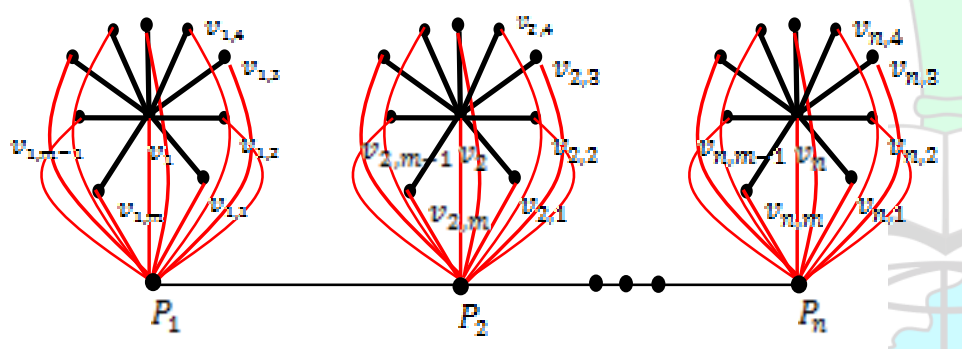

Teorema

Jika $\mathrm{G}$ adalah graf hasil operasi korona graf lintasan $\left(P_{n}\right)$ dengan $n$ titik dan graf bintang $K_{1, m}$ dengan $m$ titik, dimana $n \geq 2$ dan $m \geq 3$, maka $\operatorname{dim}(G)$ dengan $W=$

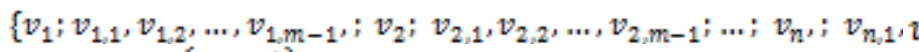
adalah $n(m-1)+n$ atau dengan kata lain $\operatorname{dim}(G)=n m$.

\section{Bukti:}

Akan dibuktikan bahwa $|W|=n m$ adalah himpunan pemisah. Representasi setiap titik pada G terhadap W adalah

$r\left(P_{1} \mid W\right)=(1 ; 1,1, \ldots, 1 ; 2 ; 2,2, \ldots, 2 ; \ldots ; n+1 ; n, n, \ldots, n)$ $r\left(P_{2} \mid W\right)=(2 ; 2,2, \ldots, 2 ; 1 ; 1,1, \ldots, 1 ; 2 ; 2,2, \ldots, 2 ; n-1 ; n-1, n-1, \ldots, n-1)$ :

$r\left(P_{n} \mid W\right)=\left(n ; n, n_{, \ldots,}, n ; n-1 ; n-1, n-1, \ldots, n-1 ; \ldots ; 1 ; 1,1\right.$ dengan

$\|W\|=n(m-2)+n=n m-n . \quad$ Representasi setiap titik di $G$ terhadap $W$ adalah
$r\left(P_{1} \mid W\right)=\left(1 ; 1,1 ; \ldots, 1 ; 2 ; 2,2, \ldots, 2 ; \ldots ; n+1 ; n, n_{s, \ldots} n\right)$

$r\left(P_{2} \mid W\right)=(2 ; 2,2, \ldots, 2 ; 1 ; 1,1, \ldots, 1 ; 2 ; 2,2, \ldots, 2 ; n-1 ; n-1, n-1, \ldots$ !

$r\left(P_{n} \mid W\right)=\left(n ; n, n_{s,}, n ; n-1 ; n-1, n-1, \ldots, n-1 ; \ldots ; 1 ; 1,1, \ldots, 1\right)$ $r\left(v_{1, m-1} \mid W\right)=(1 ; 2,2, \ldots 2 ; 3 ; 3,3, \ldots 3 ; \ldots ; n+1 ; n+1, n+1, \ldots, n+$ $r\left(v_{1, m} \mid W\right)=(1 ; 2,2, \ldots 2 ; 3 ; 3,3, \ldots 3 ; \ldots ; n+1 ; n+1, n+1, \ldots, n+1$. $r\left(v_{2 m-1} \mid W\right)=(3 ; 3,3, \ldots 3 ; 1 ; 2,2, \ldots 2 ; \ldots ; n ; n, n, \ldots n)$ $r\left(v_{2, m} \mid W\right)=(3 ; 3,3, \ldots 3 ; 1 ; 2,2, \ldots 2 ; \ldots ; n ; n, n, \ldots n)$ !

$r\left(v_{n, m-1} \mid W\right)=\left(n+1 ; n+1, n+1, \ldots, n+1 ; n ; n, n_{, \ldots} n_{; \ldots} ; 1 ; 2 ; 2\right.$, $r\left(v_{n, m} \mid W\right)=\left(n+1_{s} n+1_{s} n+1_{v \ldots s} n+1_{s} n_{j} n_{s} n_{s \ldots} n_{j} \ldots ;, 1 ; 2 ; 2,2, \ldots, 2\right)$

\section{Karena} ada

$v_{1, m}, v_{1, m-1} ; v_{2, m}, v_{2, m-1} ;$ dan $v_{n, m}, v_{n, m-1}$ dan $v_{1, m} \neq v_{1, m} ; v_{2, m} \neq v_{2, m-1} ;$ dan $v_{n, m} \neq$

$v_{n, m-1}$

tetapi,

$r\left(v_{1, m} \mid W\right)=r\left(v_{1, m-1} \mid W\right) ;$

$r\left(v_{2 m} \mid W\right)=r\left(v_{2 m-1} \mid W\right)$;

dan $r\left(v_{n, m} \mid W\right)=r\left(v_{n, m-1} \mid W\right)$ maka $W$ dengan kardinalitas $n(m-4)$ bukan himpunan pemisah.

Oleh karena itu, tidak terdapat himpunan pemisah dengan kardinalitas kurang dari $\mathrm{nm}$, sehingga $W$ dengan kardinalitas $\mathrm{nm}$ adalah himpunan pemisah dengan kardinalitas minimum.

Jadi, terbukti jika $G$ adalah graf hasil operasi korona graf lintasan $\left(P_{n}\right)$ dengan $n$ titik dan graf 
bintang $K_{1 m}$ dengan $m$ titik, dimana $n \geq 2$ dan $m \geq 3$, maka $\operatorname{dim}(G)$ dengan $W=$

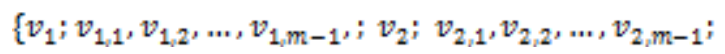

$\left.\ldots v_{n, w} v_{n, 1}, v_{n, 2}, \ldots, v_{n, m-1}\right\} \quad$ adalah

$n(m-1)+n$ atau dengan kata lain $\operatorname{dim}(G)=n m$.

\section{PENUTUP}

\section{Simpulan}

Berdasarkan pembahasan yang telah dipaparkan sebelumnya, maka dapat diambil kesimpulan sebagai berikut:

a. Misalkan $G$ adalah graf, dimensi metrik pada graf $G$ yang dinotasikan dengan $\operatorname{dim}(G)$ adalah kardinalitas minimum dari semua himpunan pemisah.

b. Operasi korona pada dua buah graf $\mathrm{G}$ dan $\mathrm{H}$, dinotasikan dengan $G \odot H$, didefinisikan sebagai graf yang diperoleh dari salinan p-simpul graf $\mathrm{G}$ dan $\mathrm{p}$ salinan $H_{1}, H_{2}, \ldots, H_{\mathrm{p}}$ dari $\mathrm{H}$, yang kemudian bergabung dengan i-simpul dari $G$ untuk setiap simpul di $H_{\bar{i}}$.

c. Jika $G$ adalah graf hasil $\left(P_{n} \odot C_{m}\right)$ dengan $n \geq 2$ dan $m \geq 5$, maka $\operatorname{dim}(G)=n(m-3)$. d. Jika $\mathrm{G}$ adalah graf hasil $\left(P_{n} \odot K_{1, m}\right)$ dengan $n \geq 2$ dan $m \geq 3$, maka $\operatorname{dim}(G)=n m$.

\section{DAFTAR PUSTAKA}

Eka dan Budi, Dimensi Metrik Pada Graf Lintasan, Graf Komplit, Graf Sikel, Graf Bintang dan Gran Bipartit Komplit, UNESA, 2013.

D. Fajjria, I. Muzayyana, Dimensi Metrik Grup Lintasan Tak Hingga, UIN Malang, 2010.

Melati, Rani Arum, Resolving Set dan Dimensi Metrik Graf Lengkap, Graf Lintasan dan Graf Bipartit Lengkap, Universitas Andalas, 2011.

Saputro, S.W., dkk., The metric dimension of a complete n-partite graphs and its product, ITB, 2009. 
Silviana Maya P. ${ }^{1}$, Syarifuddin N. Kapita ${ }^{2}$ : Dimensi Metrik pada Hasil Operasi Korona Dua Buah Graf

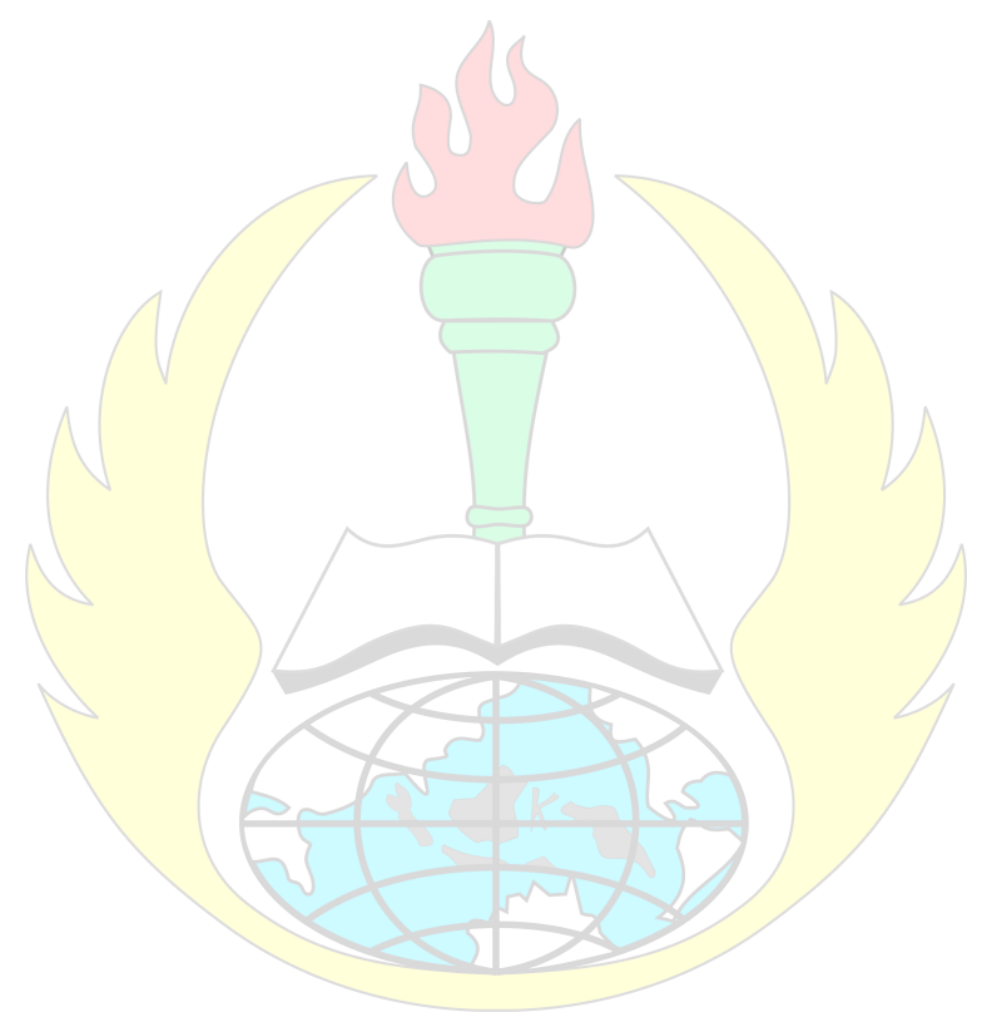

